\title{
DISTORTIONAL HARDENING MATERIAL MODEL FOR UNIDIRECTIOALLY REINFORCED CFRTP CONSIDERED FROM THE RESULTS OF NUMERICAL MATERIAL TESTING
}

\author{
$\underline{\text { Koji Yamamoto }^{1 *}}$, Masato Somemiya $^{2}$, Seishiro Matsubara ${ }^{3}$, Norio Hirayama $^{2}$, Kenjiro Terada ${ }^{4}$ \\ ${ }^{1}$ CYBERNET SYSTEMS CO., LTD. \\ ${ }^{2}$ Nihon University \\ ${ }^{3}$ Nagoya University \\ ${ }^{4}$ Tohoku University \\ *yamamo-k@cybernet.co.jp
}

Macroscopic stress strain-curves of thermoplastic epoxy resin reinforced by unidirectional carbon fiber (CFRTP) was investigated via numerical material testing (NMT) based on homogenization theory. The results suggested that CFRTP has unique hardening properties, which cannot be described with the existing conventional anisotropic elastoplastic constitutive law. To represent them, we employ bimodal plasticity theory proposed by Dvorak et al. [1] for the initial yield function and combine it with distortional hardening law [2]. Figure 1 shows the initial yield surface and the subsequent yield surface after hardening by uniaxial tensile loading in the transverse direction, both of which have been obtained from NMT. Fitting results by the proposed constitutive law and Hill plasticity with isotropic hardening are also shown in the same figure. It was confirmed that proposed constitutive law is capable of reproducing the peculiar hardening behaviour of CFRTP more accurately than the conventional model.

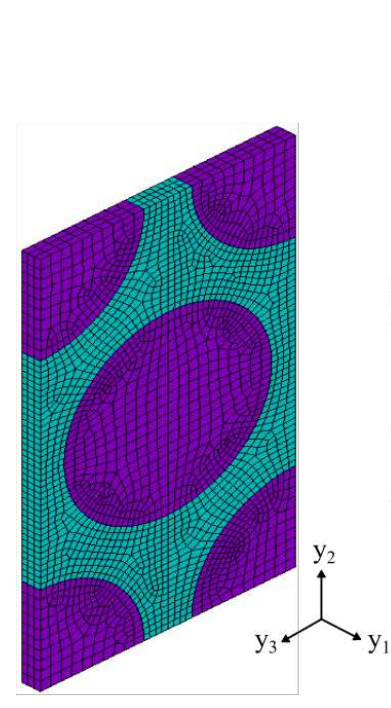

(a) FE model for microstructure

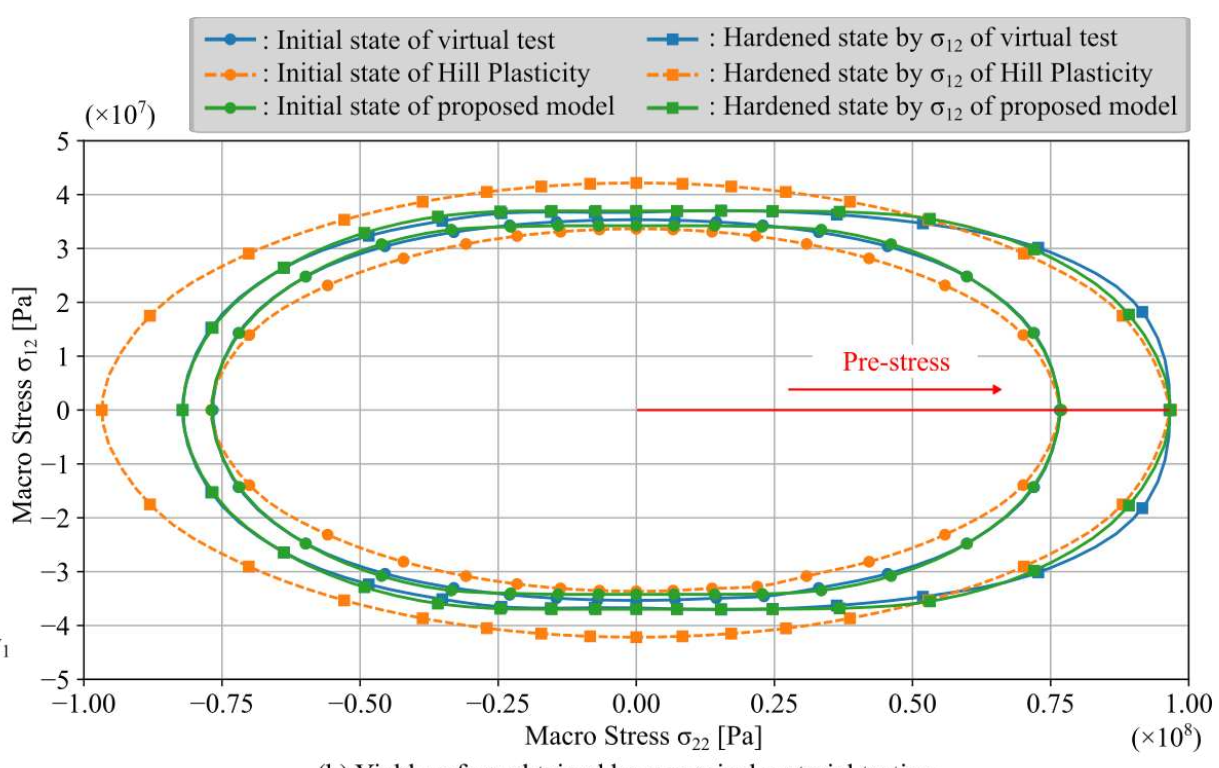

(b) Yield surface obtained by numerical material testing

Figure 1. FE model and yield surface for initial and hardening state after uniaxial loading.

\section{References}

[1] G.J. Dvorak and Y.A. Bahei-El-Din (1987) A Bimodal Plasticity Theory of Fibrous Composite Materials. Acta Mechanica, 69, 219-241.

[2] A.V. Shutov and J. Ihlemann A viscoplasticity model with an enhanced control of the yield surface distortion. International Journal of Plasticity, 39, 152-167. 